\title{
Repositionable Compounds with Antifungal Activity against Multidrug Resistant Candida auris Identified in the Medicines for Malaria Venture's Pathogen Box
}

\author{
Gina Wall, Natalia Herrera and José L. Lopez-Ribot*(i) \\ Department of Biology and South Texas Center for Emerging Infectious Diseases, The University of Texas at \\ San Antonio, San Antonio, TX 78249, USA; gina.wall@utsa.edu (G.W.); n-herrera@live.com (N.H.) \\ * Correspondence: jose.lopezribot@utsa.edu; Tel.: +1-210-458-7022
}

Received: 16 September 2019; Accepted: 29 September 2019; Published: 1 October 2019

\begin{abstract}
Background. Candida auris has spread rapidly around the world as a causative agent of invasive candidiasis in health care facilities and there is an urgent need to find new options for treating this emerging, often multidrug-resistant pathogen. Methods. We screened the Pathogen Box ${ }^{\circledR}$ chemical library for inhibitors of $C$. auris strain 0390, both under planktonic and biofilm growing conditions. Results. The primary screen identified 12 compounds that inhibited at least $60 \%$ of biofilm formation or planktonic growth. After confirmatory dose-response assays, iodoquinol and miltefosine were selected as the two main leading repositionable compounds. Iodoquinol displayed potent in vitro inhibitory activity against planktonic $C$. auris but showed negligible inhibitory activity against biofilms; whereas miltefosine was able to inhibit the growth of $C$. auris under both planktonic and biofilm-growing conditions. Subsequent experiments confirmed their activity against nine other strains C. auris clinical isolates, irrespective of their susceptibility profiles against conventional antifungals. We extended our studies further to seven different species of Candida, also with similar findings. Conclusion. Both drugs possess broad spectrum of activity against Candida spp., including multiple strains of the emergent $C$. auris, and may constitute promising repositionable options for the development of novel therapeutics for the treatment of candidiasis.
\end{abstract}

Keywords: Candida auris; antifungals; drug screening; Pathogen Box; repurposing

\section{Introduction}

Candidiasis is the third to fourth most common cause of nosocomial bloodstream infections in hospitalized patients in the United States [1-4], and invasive candidiasis carries mortality rates close to $40 \%$ [5]. Due to its prevalence and high morbidity and mortality rate, this infection presents a great challenge to clinicians. Even though Candida albicans is the main causative agent for these infections, infections caused by non-albicans Candida species (NACS) have increased in the last few decades, currently accounting for approximately half of the cases [6]. The most recent NACS to emerge as a formidable opportunistic pathogen is Candida auris. It was first reported in a human ear infection in 2009 in Japan [7], although it has been determined retroactively that it was present in an infection in South Korea in 1996 [8]. After its first identification, C. auris has since emerged throughout the world and become a major threat causing outbreaks of infections in hospitals and health care facilities worldwide [9-17]. There are several reasons that have contributed to the rapid spread of $C$. auris. First, unlike its distant relative $C$. albicans, $C$. auris is able to live on surfaces outside the human body for many weeks and remain on human skin for extended periods of time even after treatment, further complicating the management of these fungal infections [18-23]. For example, in New York City from 2013-2017, an outbreak of C. auris was monitored, and colonization was identified frequently as 
well as environmental contamination [24]. In the same outbreak, the mortality rate was $45 \%$ with $98 \%$ of cases having resistance to fluconazole. The second contributing factor is the difficulty in correctly identifying C. auris, which in the past had often been misidentified by commercial systems as other close species (i.e., C. haemulonii), possibly causing incorrect treatment regimens to be instituted thereby allowing the infection to persist $[25,26]$. The frequent antifungal resistance seen in $C$. auris represents a third contributing factor to its emergence and high mortality rates [27]. For example, it has been reported by the Centers for Disease Control and Prevention that $90 \%$ of C. auris strains in the U.S. have been resistant to fluconazole, $30 \%$ have been resistant to amphotericin $\mathrm{B}$, and $5 \%$ have been resistant to echinocandins [28]. Thus, the fact that even some strains of $C$. auris can be resistant to all three major classes of clinically-used antifungals agents is a cause of great concern to the healthcare community $[29,30]$. Finally, C. auris has been shown to have the ability to form highly resistant biofilms, which allows for better defense against antifungals as well as immune cells [31-33].

In order to combat the increasing emergence of this fungal pathogen, it is imperative that new treatments be found. As opposed to a lengthy and expensive de novo pathway for drug discovery, repurposing or repositioning of existing drugs may represent a cost effective and faster approach to finding compounds with antifungal properties that can be readily used in patients [34-37]. To this end, here we screened The Pathogen Box ${ }^{\circledR}$ library from Medicines for Malaria Venture (MMV; https://www.mmv.org/mmv-open/pathogen-box), a diverse library of approximately 400 drug-like compounds assembled by MMV, in search for inhibitors of $C$. auris. This library is made up of drug-like molecules that have been used to treat neglected tropical diseases like cryptosporidiosis, tuberculosis, malaria, and dengue, among other diseases, as well as reference compounds including some known antifungals [38]. Since the molecules in this library are known to possess activity in human infections, it is expected that the compounds identified in this screen could represent valuable options for the fast deployment of novel treatments against the devastating infections caused by $C$. auris, which are urgently needed.

\section{Materials and Methods}

\subsection{Drug Library}

The Pathogen Box ${ }^{\circledR}$ was kindly provided by Medicines for Malaria Venture (Geneva, Switzerland). It contains 400 drug-like molecules, including reference compounds, which are known to be active against neglected diseases such as malaria, toxoplasmosis, and tuberculosis [38]. Two clinically-used antifungals, Amphotericin B and posaconazole, are also included. The molecules are provided in 96-well microtiter plates as $10 \mathrm{mM}$ solutions in dimethyl sulfoxide (DMSO). From the main library, a daughter plate was prepared by making 1:100 dilutions and stored for future experiments at $-20^{\circ} \mathrm{C}$. To make these solutions, $2 \mu \mathrm{L}$ of each molecule was diluted into $198 \mu \mathrm{L}$ of RPMI medium supplemented with L-glutamine (Cellgro, Manassas, VA, USA) and buffered with $165 \mathrm{mM}$ morpholinepropanesulfonic acid ((MOPS) Thermo-Fisher Scientific, Waltham, MA) at pH 6.9, using the wells of presterilized, polystyrene, flat-bottomed 96-well microtiter plates (Corning Incorporated, Corning, NY, USA).

\subsection{Strains and Culture Conditions}

The C. auris panel was provided by the U.S. Centers for Disease Control and Prevention [39]. From this panel, C. auris 0390 clinical isolate was chosen for initial experiments, including the primary screens, because of its designation as multidrug resistant. This clinical isolate, classified as belonging to the South Asia clade I, was found to be resistant to azoles and amphotericin B and to have decreased susceptibility against echinocandins, according to the CDC. Eleven other clinical isolates, including nine other $C$. auris isolates, one $C$. krusei, and one C. lusitaniae from the CDC panel, as well as the C. albicans SC5314 type strain, and clinical isolates representative of different NACS obtained from the Fungus Testing Laboratory at the University of Texas Health Sciences Center at San Antonio, including C. dubliniensis, C. parapsilosis, C. tropicalis, and C. glabrata, were used in follow-up experiments. 
The strains were grown overnight by inoculating cells in $20 \mathrm{~mL}$ of yeast extract-peptone-dextrose (YPD) (1\% (wt/vol) yeast extract, 2\% (wt/vol) peptone, 2\% (wt/vol) dextrose) liquid medium in 150-mL flasks and incubating in an orbital shaker $\left(150-180 \mathrm{rpm}\right.$ ) at $30^{\circ} \mathrm{C}$. After $18-20 \mathrm{~h}$, the cells were washed with phosphate-buffered saline (PBS) and counted with a hemocytometer. The cells were then diluted to the desired final density (usually $0.5 \times 10^{3}$ cells $/ \mathrm{mL}$ for planktonic testing and $1 \times 10^{6}$ for biofilm testing) in RPMI.

\subsection{Primary Screens for Inhibitors of C. auris}

The initial screens of the Pathogen Box ${ }^{\circledR}$ for antifungal activity against $C$. auris were performed under two different growing conditions, planktonic and biofilm, using two different concentrations ( 5 and $20 \mu \mathrm{M}$ ) for each condition. To test the inhibitory effect of the molecules against planktonic C. auris 0390, the 5 and $20 \mu \mathrm{M}$ screens were performed according to the CLSI document M27-A3 for antifungal susceptibility testing of yeasts [40], with minor modifications. Briefly, an inoculum of C. auris strain 0390 was prepared at $1 \times 10^{3}$ cells $/ \mathrm{mL}$ of yeast cells and added to the wells of 96 -well microtiter plates, each containing an individual compound from the Pathogen Box ${ }^{\circledR}$ at final concentrations of 5 or $20 \mu \mathrm{M}$. The plates were then incubated at $37^{\circ} \mathrm{C}$ for $48 \mathrm{~h}$, read visually (for $>50 \%$ inhibition) at 24 and $48 \mathrm{~h}$. At the end of the incubation, the cells in the wells were homogenized and the absorbance determined spectrophotometrically with a microtiter plate reader to provide a more quantitative measure of inhibition.

To test the inhibitory effect of the molecules in inhibition of biofilm formation of C. auris 0390, the primary screenings (at 5 and $20 \mu \mathrm{M}$ ) were performed according to the 96-well microtiter plate model of Candida biofilm formation previously developed by our group [41,42]. Briefly, an inoculum of $C$. auris strain 0390 was prepared at $2 \times 10^{6}$ cells $/ \mathrm{mL}$ of yeast cells, and appropriate volumes were added to wells of a flat-bottom 96-well microtiter plate containing the same volume of compounds at appropriate concentrations, so that the final concentration of cells was $1 \times 10^{6}$ cells $/ \mathrm{mL}$. The plates were then incubated at $37^{\circ} \mathrm{C}$ for $24 \mathrm{~h}$. Once incubation had ended, the plates were washed once with PBS to remove non-adherent cells, and the biofilm inhibition was estimated using a colorimetric assay on the basis of the reduction of 2,3-bis(2-methoxy-4-nitro-5-sulfo-phenyl)-2H-tetrazolium-5-carboxanilide (XTT, Sigma, St. Louis, MO, USA) over the course of $2 \mathrm{~h}$ by metabolically active cells as previously described by us [43].

For both screens, the first column (top four wells) as well as the last column (bottom four wells) served as positive controls (no compound added), while the first column (bottom four wells) and last column (top four wells) served as negative controls (no cells added), respectively. The screenings were performed at both 5 and $20 \mu \mathrm{M}$ as mentioned above. Molecules found to inhibit $60 \%$ or more growth at 24 or $48 \mathrm{~h}$ in either screen (based on absorbance readings) were initially selected as "hits".

\subsection{Dose-Response Assays for Confirmation of Initial Hits}

The confirmation of the activity of the compounds found to inhibit $C$. auris growth in the initial screens was accomplished through dose-response assays using the same microdilution techniques for inhibition of planktonic and biofilm growth as above. The starting concentration of the hits was $20 \mu \mathrm{M}$ in both dose response assays, and serial 2-fold dilutions were done across the rows of a 96-well microtiter plate from left to right down to $0.0391 \mu \mathrm{M}$. Positive and negative controls were also included. To prepare the corresponding dose-response curve in both assays, the readings obtained from the plate reader were normalized using the positive (untreated) and negative (uninoculated) controls which were arbitrarily set as $100 \%$ and $0 \%$ growth. After performing these calculations, the $\mathrm{IC}_{50}$ values, defined as the concentration of drug required to reduce either planktonic or biofilm growth by $50 \%$, were determined by fitting the normalized results to the variable slope Hill equation (an equation that determines the nonlinear drug dose-response relationship) using Prism 8 (GraphPad Software Inc., San Diego, CA, USA). 


\subsection{Activity of Resupplied Miltefosine and Iodoquinol against C. auris 0390}

For follow-up experiments, pharmaceutical grade iodoquinol and miltefosine were commercially purchased from Sigma-Aldrich, after identifying these two compounds as the most promising hits from the initial screens based on dose-response assays. For this set of experiments we tested the activity of these two drugs under three different modalities: planktonic growth and inhibition of biofilm formation (as described above), and activity against preformed biofilms, also as previously described by our group [41,42]. Briefly, C. auris 0390 was added to wells of a 96-well microtiter plate at a final concentration of $1 \times 10^{6}$ cells $/ \mathrm{mL}$ and incubated for $24 \mathrm{~h}$ to allow for biofilm formation. Once mature biofilms were formed, they were washed, and serial-dilutions of iodoquinol or miltefosine were added. The starting concentration for all three assays was $64 \mu \mathrm{g} / \mathrm{mL}$ for both drugs. The plates were read using the microtiter plate reader, with both biofilm assays being read colorimetrically using the XTT assay and the planktonic assay being read as absorbance to determine the turbidity of the wells after homogenization. As described for the dose-response assay, the readings were normalized and then the $\mathrm{IC}_{50}$ values determined using Prism.

2.6. Determination of the Activity of Miltefosine and Iodoquinol against Multiple C. auris Clinical Isolates and against Representative Strains of Different Candida Species

Both compounds were also tested against nine other C. auris clinical isolates in the CDC panel, C. krusei, and C. lusitaniae (also from the CDC panel), as well as C. albicans SC5314 type strain and representative isolates of $C$. dubliniensis, C. tropicalis, C. parapsilosis, C. glabrata. We used the same three in vitro assays (planktonic, inhibition of biofilm formation and activity against preformed biofilms) as described above.

\section{Results}

\subsection{Screening the Pathogen Box ${ }^{\circledR}$ for Inhibitors of C. auris Planktonic Growth and Biofilm Formation,} and Dose-Response Assays to Confirm the Activity of Initial Hits

We used two different 96-well microtiter plate-based models to perform initial screens of the Pathogen Box ${ }^{\circledR}$ in search for compounds with inhibitory activity against $C$. auris under two different conditions: inhibition of planktonic growth (following CLSI methodologies, [40]) and inhibition of biofilm formation (using the model originally developed in our laboratory, [41,42]). C. auris strain 0390, from the CDC panel [39], was selected for these initial screens because it shows resistance to fluconazole and amphotericin B, and also displays decreased susceptibility against echinocandins according to the CDC. The screens were performed at two different concentrations under each growth condition, 5 and $20 \mu \mathrm{M}$. Compounds in the library were identified as initial hits if they inhibited growth in either assay by $60 \%$ or greater, based on spectrophotometric (for planktonic) or colorimetric (for biofilm) readings, as compared to the uninhibited controls.

As shown in Figure 1 and Table 1, according to this criteria, we found a total of 11 compounds that inhibited C. auris planktonic growth at $20 \mu \mathrm{M}$, whereas only four of them were considered hits when screened at $5 \mu \mathrm{M}$. Likewise, a total of three compounds in the Pathogen Box ${ }^{\circledR}$ library were capable of inhibiting C. auris biofilm formation by $60 \%$ or more at $20 \mu \mathrm{M}$, with only two of those representing hits when the screen was conducted at the lower concentration, though one other compound not identified at $20 \mu \mathrm{M}$ was found at this concentration. As could be expected, all initial hits for biofilm formation overlapped with those capable of inhibiting planktonic growth. Overall, of the 400 compounds in the Pathogen Box, a total of 12 compounds fulfilled the criteria established for consideration as initial hits, resulting in a hit rate of $3 \%$. Not surprisingly, some of the best hits were the fully established, Food and Drug Administration (FDA)-approved, and clinically-used amphotericin B and posaconazole, used in this collection as the two reference antifungal drugs, which served as internal controls for validation of screening results; however, we decided to exclude them from any further testing since our main interest was in finding repositionable compounds. 
A. Inhibition of Planktonic Growth

$5 \mu \mathrm{M}$ vs $20 \mu \mathrm{M}$

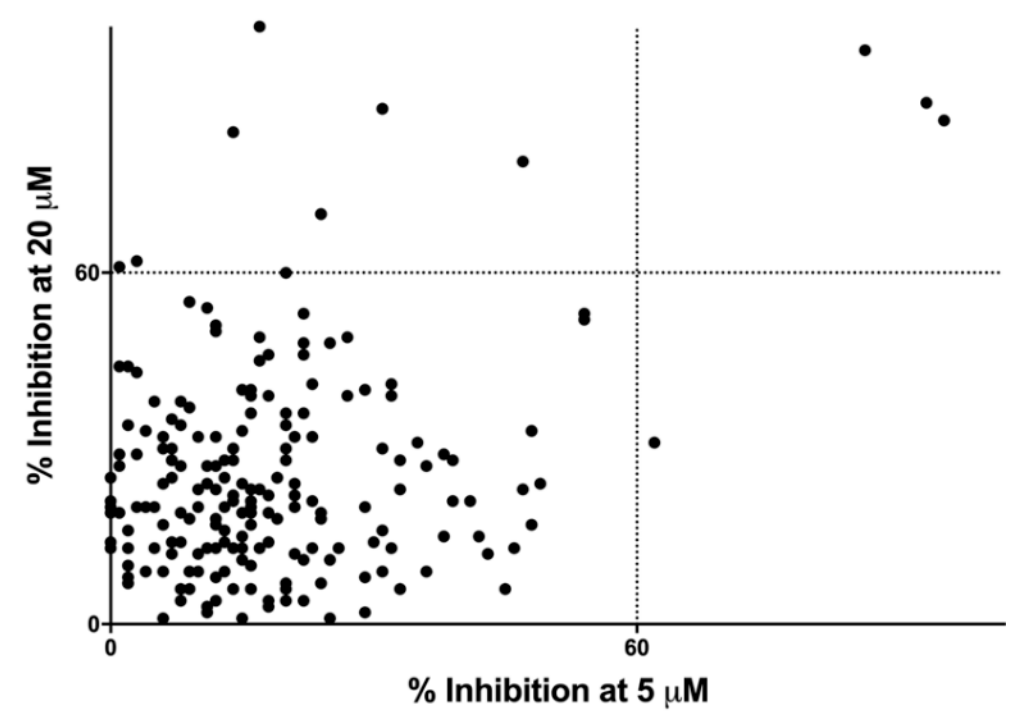

B.

Inhibition of Biofilm Formation

$5 \mu \mathrm{M}$ vs $20 \mu \mathrm{M}$

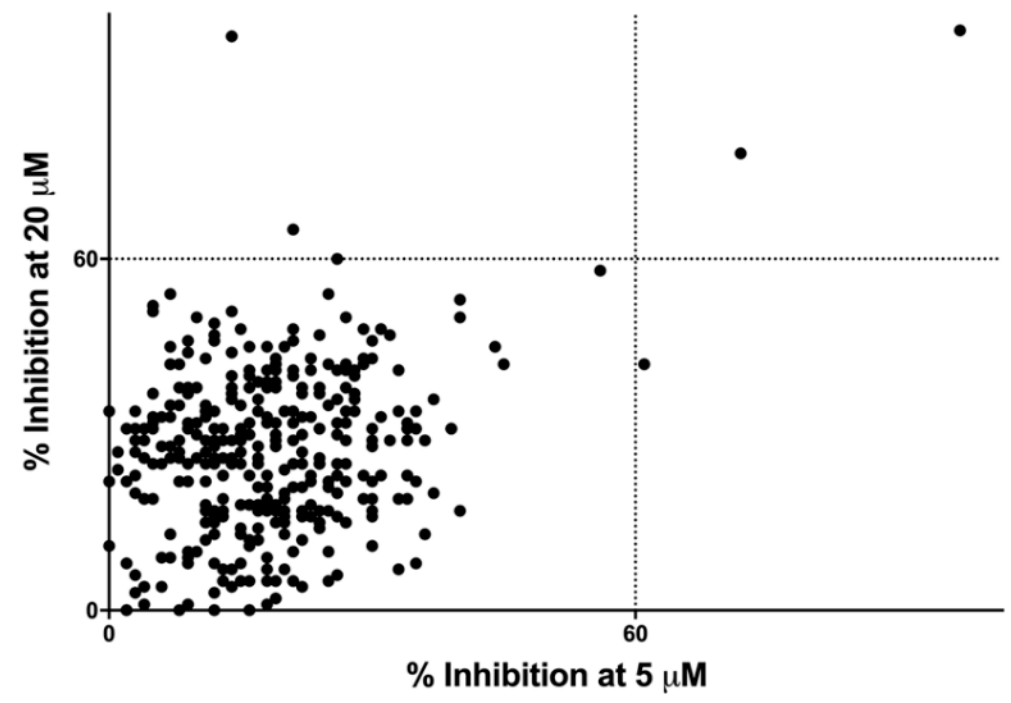

Figure 1. Graphical representation of results from primary screenings of the Pathogen Box ${ }^{\circledR}$ in search for compounds with inhibitory activity against Candida auris strain 0390 under planktonic (A) and biofilm (B) growing conditions. 
Table 1. Identity and extent of inhibition of compounds identified as "hits" during primary screenings of the Pathogen Box ${ }^{\circledR}$ in search for compounds with inhibitory activity against C. auris strain 0390 under planktonic and biofilm growing conditions.

\begin{tabular}{|c|c|c|c|c|c|}
\hline $\begin{array}{l}\text { Hit Compounds } \\
\text { Inhibition of } \\
\text { Planktonic } \\
\text { Growth }\end{array}$ & $\begin{array}{c}\text { \% Inhibition } \\
\text { of Planktonic } \\
\text { Growth at } \\
5 \mu \mathrm{M}\end{array}$ & $\begin{array}{l}\text { \% Inhibition } \\
\text { of Planktonic } \\
\text { Growth at } \\
20 \mu \mathrm{M}\end{array}$ & $\begin{array}{l}\text { Hit Compounds } \\
\text { Inhibition of } \\
\text { Biofilm } \\
\text { Formation }\end{array}$ & $\begin{array}{l}\% \text { Inhibition } \\
\text { of Biofilm } \\
\text { Formation at } \\
5 \mu \mathrm{M}\end{array}$ & $\begin{array}{c}\% \text { Inhibition } \\
\text { of Biofilm } \\
\text { Formation at } \\
20 \mu \mathrm{M}\end{array}$ \\
\hline Amphotericin B & 93 & 89 & Amphotericin B & 97 & 99 \\
\hline Posaconazole & 95 & 86 & Posaconazole & 72 & 78 \\
\hline Miltefosine & $\mathrm{n} / \mathrm{a}$ & 102 & Miltefosine & $\mathrm{n} / \mathrm{a}$ & 98 \\
\hline Iodoquinol & 86 & 98 & Iodoquinol & $\mathrm{n} / \mathrm{a}$ & $\mathrm{n} / \mathrm{a}$ \\
\hline MMV676162 & $\mathrm{n} / \mathrm{a}$ & 65 & MMV676162 & $\mathrm{n} / \mathrm{a}$ & $\mathrm{n} / \mathrm{a}$ \\
\hline Pentamidine & $\mathrm{n} / \mathrm{a}$ & 84 & Pentamidine & 61 & $\mathrm{n} / \mathrm{a}$ \\
\hline MMV102872 & $\mathrm{n} / \mathrm{a}$ & 88 & MMV102872 & $\mathrm{n} / \mathrm{a}$ & $\mathrm{n} / \mathrm{a}$ \\
\hline MMV688852 & $\mathrm{n} / \mathrm{a}$ & 70 & MMV688852 & $\mathrm{n} / \mathrm{a}$ & $\mathrm{n} / \mathrm{a}$ \\
\hline MMV687775 & $\mathrm{n} / \mathrm{a}$ & 61 & MMV687775 & $\mathrm{n} / \mathrm{a}$ & $\mathrm{n} / \mathrm{a}$ \\
\hline MMV688417 & $\mathrm{n} / \mathrm{a}$ & 60 & MMV688417 & $\mathrm{n} / \mathrm{a}$ & $\mathrm{n} / \mathrm{a}$ \\
\hline MMV659010 & 62 & $\mathrm{n} / \mathrm{a}$ & MMV659010 & $\mathrm{n} / \mathrm{a}$ & $\mathrm{n} / \mathrm{a}$ \\
\hline MMV688938 & $\mathrm{n} / \mathrm{a}$ & 62 & MMV688938 & $\mathrm{n} / \mathrm{a}$ & $\mathrm{n} / \mathrm{a}$ \\
\hline
\end{tabular}

$\mathrm{n} / \mathrm{a}$ indicates the inhibitory values below the target value of $60 \%$ inhibition.

Next, we performed dose-response assays in order to provide confirmation of the activity of the remaining 10 compounds identified as initial hits during the primary screenings, and at the same time establish their potency. These assays were also done under both growth modalities (inhibition of planktonic growth and inhibition of biofilm formation), using the same microdilution methods as above, with the highest concentration tested being $20 \mu \mathrm{M}$.

Results confirmed the activity of four of the original 10 hit compounds (Figure 2). These four confirmed compounds were pentamidine, MMV687775, miltefosine, and iodoquinol. Although a nice dose-response was obtained for pentamidine, its potency against planktonic $C$. auris was significantly lower than the other three confirmed hit compounds (Figure 2A), and under biofilm growing conditions it did not achieve a 50\% inhibition even at the highest concentration tested (Figure 2B). Similar observations were made for compound MMV687775 under planktonic conditions, barely reaching $60 \%$ inhibition even at the highest concentration tested (Figure 2A), and this compound was totally ineffective at inhibiting biofilm formation (Figure 2B). Iodoquinol displayed extremely potent activity against $C$. auris planktonic growth, with over $80 \%$ inhibition detected even at some of the lowest concentrations tested (Figure 2A); however, it was mostly ineffective at inhibiting biofilm formation (Figure 2B). Relatively similar dose-response curves were obtained for miltefosine under planktonic and biofilm growing conditions (Figure 2A,B), as treatment with this compound led to almost complete inhibition under both growth modalities at the highest concentrations tested. Based on these results and their repositioning potential, we chose to focus on miltefosine and iodoquinol for further characterization of their activity against $C$. auris. 
A. Inhibition of Planktonic Growth

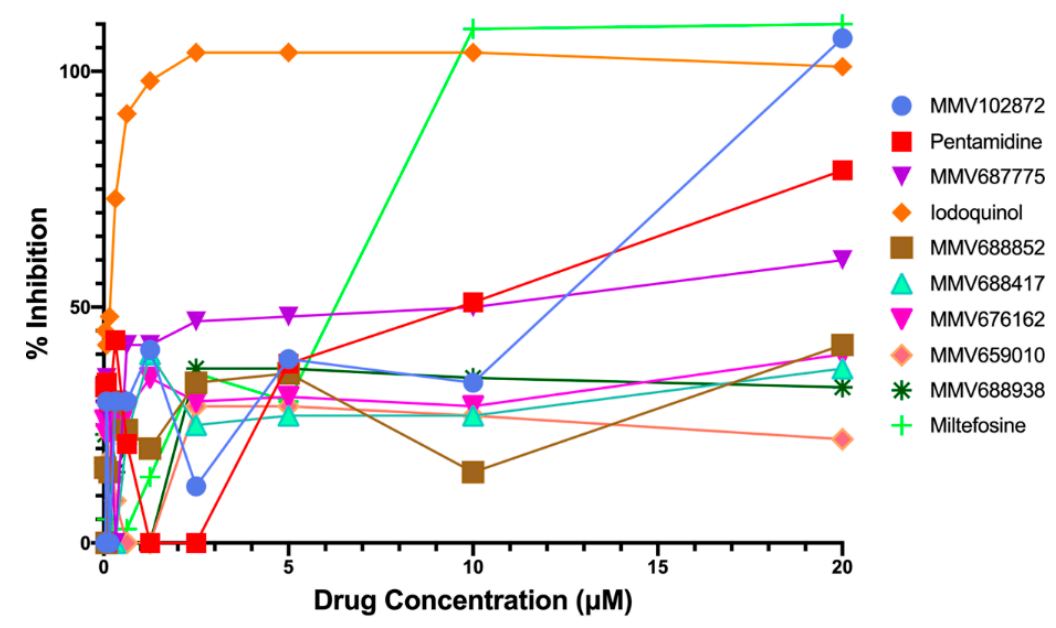

B.

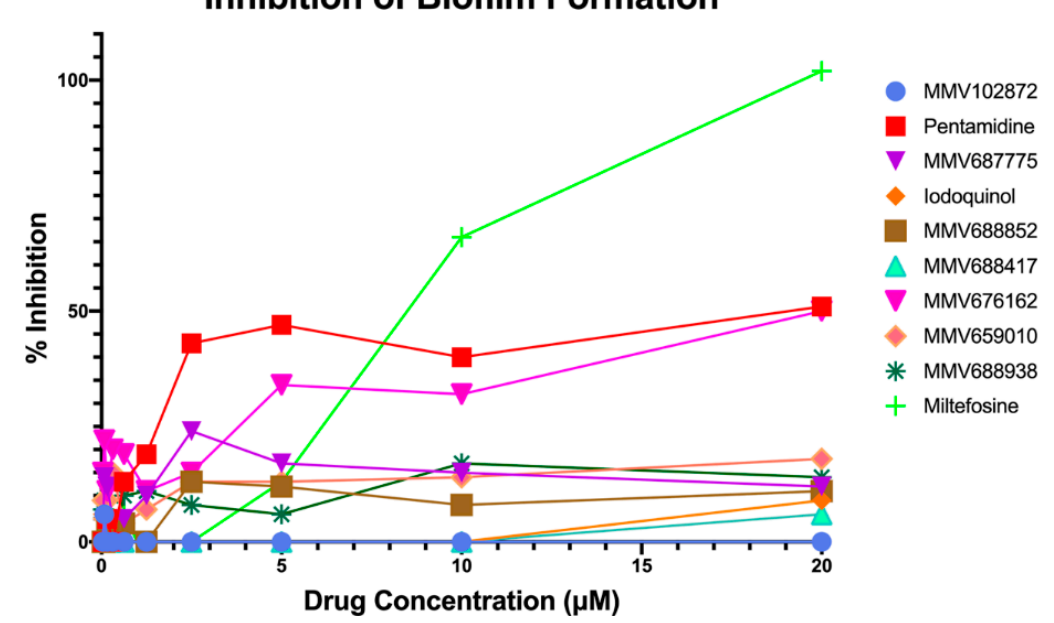

Figure 2. Results from dose-response experiments to confirm the inhibitory activity and determine the potency of initial hit compounds from primary screening against C. auris strain 0390 under planktonic (A) and biofilm (B) growing conditions.

\subsection{Follow-Up Studies with Miltefosine and Iodoquinol to Ascertain Their Inhibitory Activity against C. auris}

Both miltefosine and iodoquinol are available from different commercial sources, and we purchased these compounds in order to ascertain their activity against $C$. auris and to secure enough quantities for additional follow-up studies. We performed similar dose-response experiments with the newly commercially purchased, pharmaceutical grade compounds in order to determine their inhibitory effect against the same strain of $C$. auris, under the same two different growing conditions (planktonic and inhibition of biofilm formation), and also extended these observations to a third treatment modality (activity against preformed biofilms). As seen in Figure 3A, and confirming our previous results, miltefosine was found to completely abolish planktonic growth and biofilm formation at relatively low concentrations $(4 \mu \mathrm{g} / \mathrm{mL})$, with over $60 \%$ inhibition of planktonic growth observed at $2 \mu \mathrm{g} / \mathrm{mL}$. At $16 \mu \mathrm{g} / \mathrm{mL}$, miltefosine was able to reduce close to $90 \%$ of metabolic activity of a preformed C. auris biofilm. Iodoquinol, on the other hand, was found mostly ineffective against $C$. auris biofilms, displaying virtually no activity against pre-formed biofilms and less than $80 \%$ inhibition of biofilm formation even at the highest concentration tested $(64 \mu \mathrm{g} / \mathrm{mL})$. On the other hand, it showed very potent activity against $C$. auris planktonic growth, with over $60 \%$ inhibition at concentrations as low as $1 \mu \mathrm{g} / \mathrm{mL}$, and almost complete inhibition of proliferation at concentrations of $4 \mu \mathrm{g} / \mathrm{mL}$ and higher (Figure 3B). 

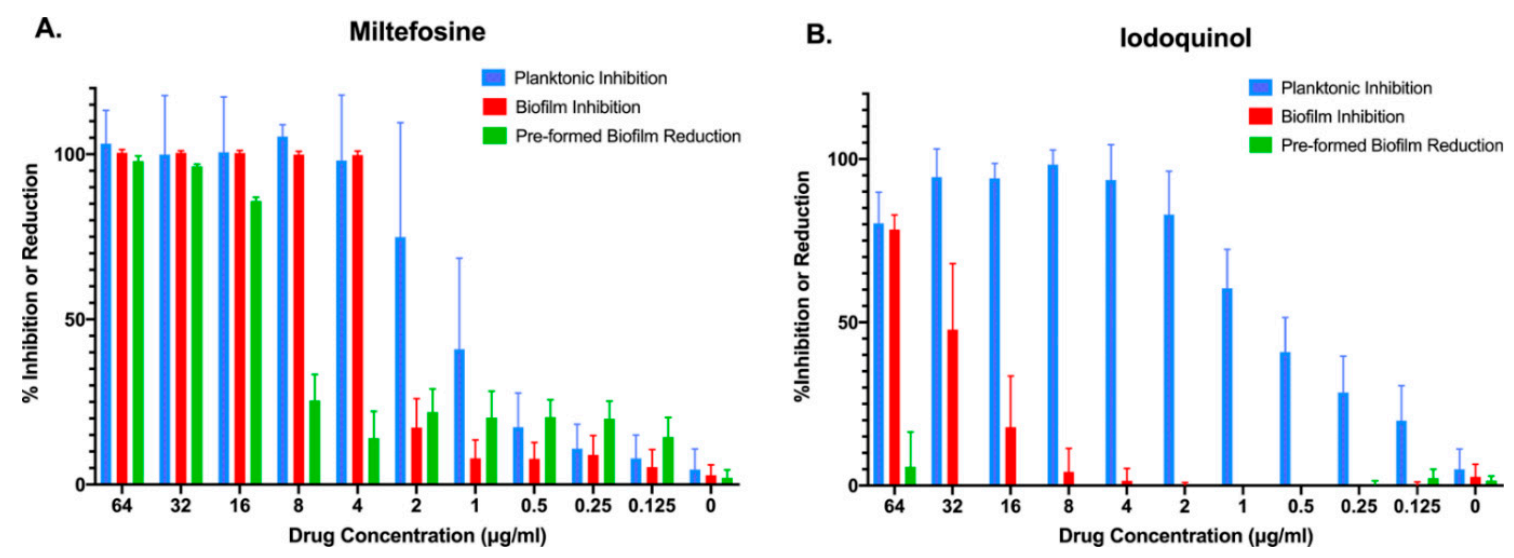

Figure 3. Activity of the two main repositionable compounds miltefosine and iodoquinol against C. auris strain 0390, under the three different growing conditions: inhibition of planktonic growth (blue bars), inhibition of biofilm formation (red bars), and activity against preformed biofilms (green bars).

We then extended our observations and examined the activity of miltefosine and iodoquinol against all other nine $C$. auris strains in the CDC panel (numbered 0381-0389, with different origins and patterns of susceptibility against conventional antifungals), also under the same three different treatment modalities: planktonic, inhibition of biofilm and activity against preformed biofilms. From the resulting dose-response curves, we calculated the corresponding $\mathrm{IC}_{50}$ values (the concentration of drug required to reduce growth of each strain by half).

As shown in Table 2, results of susceptibility testing obtained for the different strains tested were mostly comparable to those previously observed for $C$. auris strain 0390 . Iodoquinol displayed potent activity against planktonic growth of all strains tested, with $\mathrm{IC}_{50}$ values generally lower than $1 \mu \mathrm{g} / \mathrm{mL}$; with slightly elevated values around $2 \mu \mathrm{g} / \mathrm{mL}$ detected for strains 0383,0384 , and 0385 . Similar $\mathrm{IC}_{50}$ values, ranging from 1 to $2 \mu \mathrm{g} / \mathrm{mL}$ for all strains in the CDC panel, were calculated for planktonic growth in the case of miltefosine. Confirming our previous results, iodoquinol displayed rather poor anti-biofilm activity, with $\mathrm{IC}_{50}$ values for inhibition of biofilm formation generally over $20 \mu \mathrm{g} / \mathrm{mL}$, and little to no activity against preformed biofilms of all different $C$. auris strains tested. On the other hand, miltefosine exhibited excellent biofilm-inhibitory activity against all strains tested, with $\mathrm{IC}_{50}$ values similar or only about one tube dilution higher (ranging from 1 to $6 \mu \mathrm{g} / \mathrm{mL}$ ) to those that inhibited planktonic growth. Notably, relatively low $\mathrm{IC}_{50}$ values ranging from 9 to $15 \mu \mathrm{g} / \mathrm{mL}$ were calculated when the activity of miltefosine against preformed biofilms formed by the different $C$. auris strains was evaluated, with the exception of strain 0388 , for which the drug showed a slightly elevated $\mathrm{IC}_{50}$ of $20.98 \mu \mathrm{g} / \mathrm{mL}$. 
Table 2. Calculated $\mathrm{IC}_{50}$ values for the two main repositionable compounds miltefosine and iodoquinol against different $C$. auris strains from the CDC panel, under the three different growing conditions: inhibition of planktonic growth, inhibition of biofilm formation, and activity against preformed biofilms. Values are in $\mu \mathrm{g} / \mathrm{mL}$.

\begin{tabular}{ccccccc}
\hline C. auris Strain & \multicolumn{2}{c}{$\begin{array}{c}\text { IC } \\
\text { Planktonic Growth }\end{array}$} & \multicolumn{2}{c}{$\begin{array}{c}\text { IC Inhibition of } \\
\text { Biofilm Formation }\end{array}$} & \multicolumn{2}{c}{$\begin{array}{c}\text { Inhibition of } \\
\text { Pre-Formed Biofilms }\end{array}$} \\
\hline & Miltefosine & Iodoquinol & Miltefosine & Iodoquinol & Miltefosine & Iodoquinol \\
\hline $\mathbf{0 3 8 1}$ & 0.9237 & 0.7959 & 1.158 & 24.47 & 9.144 & $>64$ \\
$\mathbf{0 3 8 2}$ & 2.472 & 0.4489 & 4.988 & 27.79 & 14.69 & $>64$ \\
$\mathbf{0 3 8 3}$ & 1.379 & 1.571 & 1.702 & 52.12 & 9.449 & $>64$ \\
$\mathbf{0 3 8 4}$ & 1.404 & 2.006 & 2.645 & 56.02 & 9.214 & $>64$ \\
$\mathbf{0 3 8 5}$ & 2.149 & 1.565 & 4.656 & 33.60 & 14.84 & 38.58 \\
$\mathbf{0 3 8 6}$ & 2.152 & 0.8520 & 4.538 & 25.88 & 14.59 & 49.11 \\
$\mathbf{0 3 8 7}$ & 2.265 & 0.7733 & 5.160 & 14.50 & 13.91 & $>64$ \\
$\mathbf{0 3 8 8}$ & 2.129 & 0.4545 & 5.374 & 25.37 & 20.98 & $>64$ \\
$\mathbf{0 3 8 9}$ & 2.139 & 0.6701 & 6.049 & 9.159 & 13.62 & $>64$ \\
$\mathbf{0 3 9 0}$ & 1.984 & 0.2972 & 3.932 & 43.40 & 13.91 & $>64$ \\
\hline
\end{tabular}

\subsection{Activity of Miltefosine and Iodoquinol against Multiple Candida Species}

Besides C. auris, we were interested in assessing the inhibitory activity of our two main leading compounds against a number of Candida species that are also involved in human disease. Thus, we chose seven other species of Candida to test the compounds against in addition to C. auris 0390 (for comparison purposes). These included C. albicans strain SC5314, as well as clinical isolates of C. dubliniensis, C. parapsilosis, C. tropicalis, C. glabrata (obtained from the Fungus Testing Laboratory), and C. krusei, and C. lusitaniae (from the CDC panel). Again, we performed the three different methods for determining the activity against planktonic, inhibition of biofilm formation, and preformed biofilms. We found that miltefosine was effective at inhibiting growth, both under planktonic and biofilm growing conditions, of all Candida species tested, with the exception of $C$. lusitaniae (Figure 4A,B). Interestingly, in the case of preformed biofilms, miltefosine displayed the highest levels of activity against $C$. auris, although it was also active at higher concentrations against mature biofilms formed by C. albicans, C. krusei, C. dubliniensis, and C. tropicalis, with minimal activity against $C$. glabrata and virtually no activity against preformed biofilms of both C. lusitaniae and C. parapsilosis (Figure 4C).

In the case of iodoquinol, results demonstrated its in vitro efficacy against most Candida species tested when growing under planktonic conditions, with the notable exception of $C$. dubliniensis. We note that in the case of $C$. albicans we observed a paradoxical effect at the highest concentrations of iodoquinol tested. Regarding the ability of iodoquinol to inhibit biofilm formation, we observed different degrees of inhibition depending on the species, with higher activity against $C$. albicans and moderate activity against C. lusitaniae, C. krusei, and C. glabrata; although we note that this activity was detected at relatively high concentrations (Figure 5A,B). As expected from initial results with C. auris, iodoquinol was mostly ineffective against preformed biofilms from all species tested (Figure 5C). 
A. Inhibition of Planktonic Growth Candida Species Miltefosine

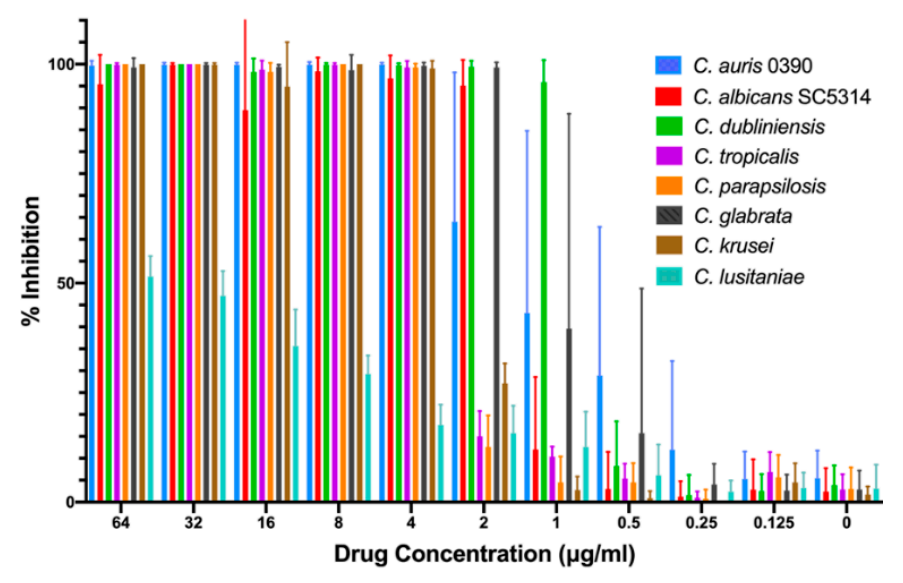

B. Inhibition of Biofilm Formation Candida Species Miltefosine

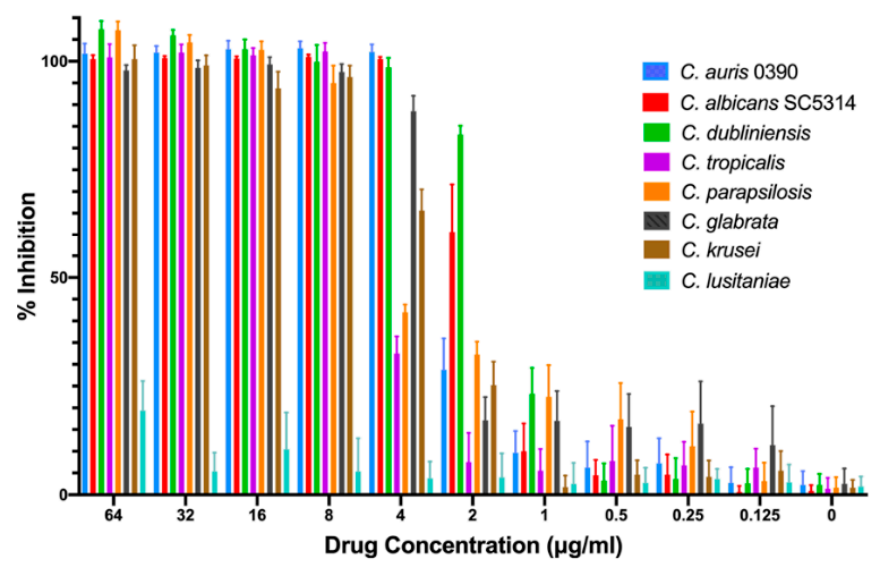

C. Reduction of Pre-formed Biofilms Candida Species Miltefosine

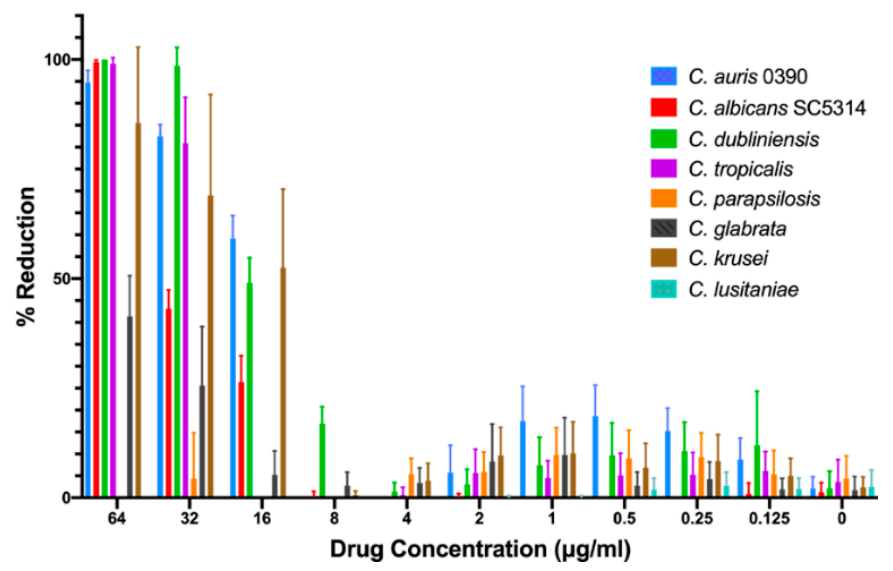

Figure 4. Activity of miltefosine against representative strains from different Candida spp. under the three different growing conditions: inhibition of planktonic growth (A), inhibition of biofilm formation (B), and activity against preformed biofilms (C). 
A. Inhibition of Planktonic Growth Candida Species lodoquinol

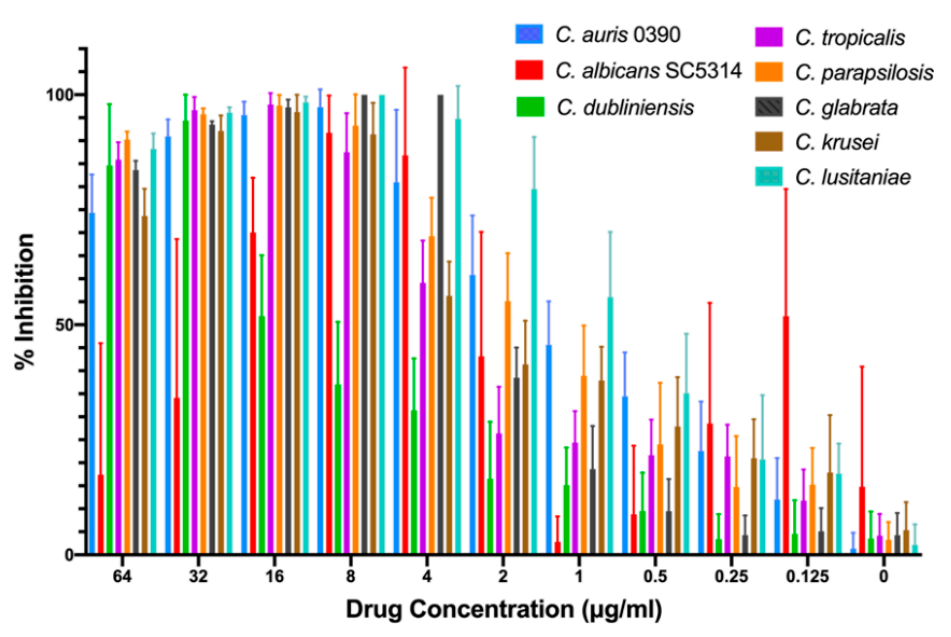

B. Inhibition of Biofilm Formation Candida Species lodoquinol

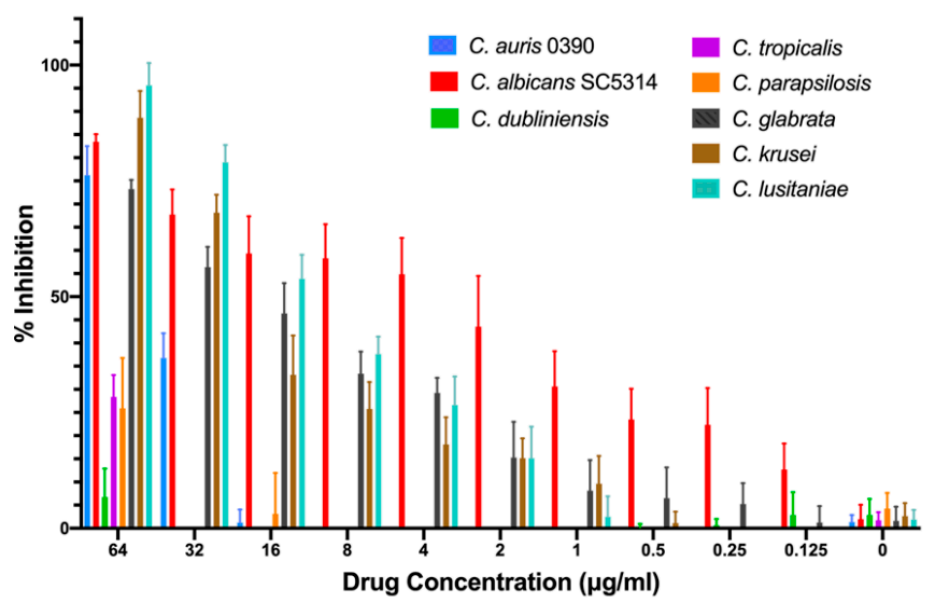

C. Reduction of Pre-formed Biofilms Candida Species lodoquinol

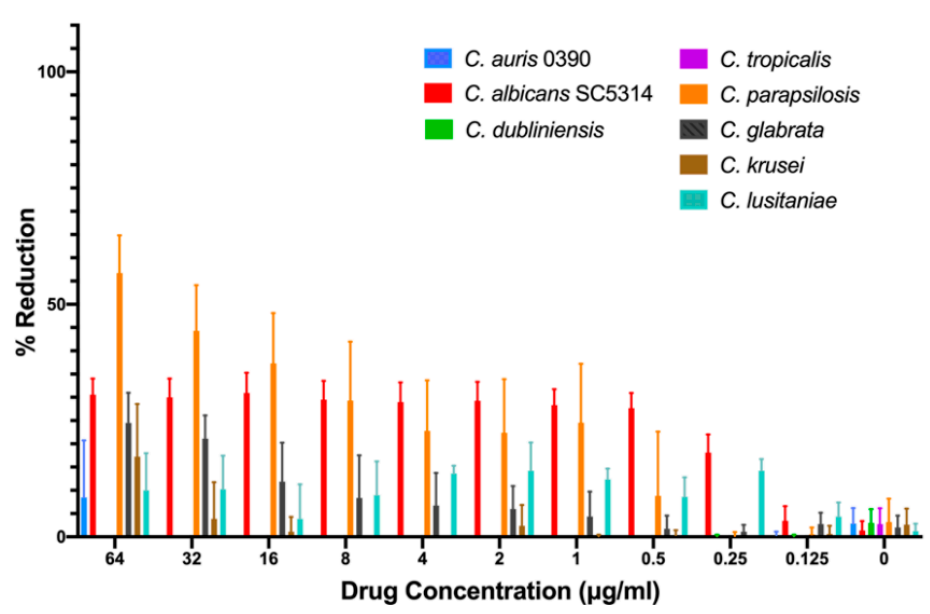

Figure 5. Activity of iodoquinol against representative strains from different Candida spp. under the three different growing conditions: inhibition of planktonic growth (A), inhibition of biofilm formation (B), and activity against preformed biofilms (C). 


\section{Discussion}

Since its first identification approximately 10 years ago, $C$. auris has emerged as a major cause of outbreaks of invasive candidiasis in healthcare facilities around the globe. These infections carry very high mortality rates, as high as $60 \%$ in some cases [9]. Given the paucity of clinically-used antifungal drugs, and since $C$. auris clinical isolates often exhibit high levels of resistance to multiple classes of antifungal drugs $[29,33,44,45]$, there is dire and urgent need to identify compounds with activity against this devastating emerging pathogen. Repurposing (or repositioning) already existing drugs used to treat other ailments as antifungals represents a fast and economical alternative to bring drugs with novel antifungal activity from the bench to the bedside [34].

To this end, here we screened the Pathogen Box ${ }^{\circledR}$ in search for drug-like molecules with inhibitory activity against $C$. auris. The Pathogen Box ${ }^{\circledR}$ is a diverse library of compounds ( 400 drug-like molecules) originally assembled by MMV with the intention to accelerate the identification of drugs with in vitro activity against neglected diseases caused by parasites (eukaryotes), including Malaria, Leishmaniasis, and Chagas's disease; worms, including Schistosoma mansoni and hookworm; and bacteria (prokaryotes; Mycobacterium tuberculosis). Some of the drugs in the library are effective against different classes/phyla and this encouraged us to search for activity against $C$. auris. Our group has previously reported on the identification of C. albicans biofilm inhibitors from the Pathogen Box ${ }^{\circledR}[46]$, and the Kronstad group has also screened this same library for the identification of compounds with antifungal activity against both C. albicans and Cryptococcus neoformans [47]. As one of the factors contributing to the pathogenesis of $C$. auris is the formation of biofilms, and biofilms formed by this species are intrinsically resistant to all clinically-used antifungal agents $[21,31,33]$, we initially decided to screen the library for inhibitors of $C$. auris growth under both planktonic and biofilm-growing conditions. Our initial screens resulted in the identification of 10 initial hit compounds with no primary antifungal designation that inhibited growth of $C$. auris by over $60 \%$ under either or both assay conditions; and results of subsequent confirmatory experiments confirmed the dose-response activity for four of them. Of these, miltefosine and iodoquinol represented the two leading repositionable compounds which we selected for a more in-depth characterization of their in vitro antifungal activity in follow-up experiments.

Miltefosine (also referred as hexadecylphosphocholine, see Supplementary Figure S1) is an alkylphosphocholine drug originally developed as an anti-cancer drug, although its side effects (particularly liver toxicity) limited its utility for this purpose [48-51]. It was shown to possess activity against various parasites, most notably Leishmania spp. Miltefosine was approved for use in India in 2002 and more recently in the United States in 2014, and it is presently marketed by Zentaris GmbH (as Impavido) as a the first oral therapy of visceral and cutaneous leishmaniasis [52-60]. Depending on weight, Impavido is given at a dose of $50 \mathrm{mg}$ 2-3 times a day for the treatment of leishmaniasis [61]. This treatment strategy allows for serum levels of up to $75.9 \mu \mathrm{g} / \mathrm{mL}$ in adults [61], and thus even the relatively high concentrations at which we observed activity against biofilms of $C$. auris and other Candida spp. should be achievable in patients. Miltefosine has dose-limiting gastrointestinal toxicity, but side effects are normally moderate in severity. It may also lead to hepatotoxicity and nephrotoxicity at very high doses. The drug was found to effect fertility in rats, although it has yet to be established whether humans can be similarly affected. In addition, it is not advised that this drug be taken during pregnancy or nursing as it can cause fetal mortality as well as adverse effects in infants [61]. Miltefosine has also been used successfully in a limited number of cases of the extremely rare highly lethal brain infection by the amoeba Naegleria fowleri and, in the United States, has orphan drug status for the treatment of other amebic infections [62]. Our group and others have previously described the antifungal activity of miltefosine [63-68]. Iodoquinol (also referred to as diiodohydroxyquinoline) is an halogenated quinoline derivative (see Supplementary Figure S1) that is used as an intestinal antiparasitic drug, mainly in the treatment of Entamoeba histolytica infections [69], apparently acting by chelation of ferrous ions essential for metabolism. Its poor intestinal absorption and side effects including on the central nervous system (i.e., seizures, and encephalopathy) and eye damage (optic atrophy leading to irreversible visual deterioration), have limited its systemic use [70]. 
In spite of these problems, it is used in topical creams to treat bacterial and fungal infections of the skin [71], and has recently been examined as a repositionable candidate for the treatment of multidrug resistant Neisseria gonorrhoeae [72]. We note that these two compounds were not identified before in previous screens against C. albicans and C. neoformans of the same Pathogen Box ${ }^{\circledR}$ library [46,47].

Our in vitro tests confirmed the potent activity of iodoquinol against $C$. auris when growing planktonically, although the drug generally lacked biofilm inhibitory activity (Figure 3A). These findings are similar to those previously reported by our group for Ebselen, whose activity against planktonic C. auris was recently identified by our group after screening another repurposing library, the Prestwick library [73]; and most recently a different group also reported on the identification of several off-patent compounds with novel antifungal activity against planktonic $C$. auris after screening the same Prestwick library [74]. On the other hand, miltefosine displayed potent inhibitory activity against C. auris under both planktonic and biofilm-growing conditions (Figure 3B). However, perhaps the most remarkable finding was the activity of miltefosine, at concentrations that are achievable in patients [75], against preformed biofilms of C. auris (Figure 3B). This is particularly interesting since once formed these biofilms are notoriously difficult to treat due to their intrinsic resistance to all currently used antifungals [31,33]. These observations were not restricted to a single strain of $C$. auris, as all clinical isolates tested from the CDC panel showed similar in vitro susceptibility profiles for iodoquinol and miltefosine (Table 2). Moreover, both our leading repositionable candidates showed activity against a majority of Candida species (Figures 4 and 5).

In summary, we identified iodoquinol and miltefosine as our leading repositionable candidates in the Pathogen Box ${ }^{\circledR}$ for the treatment of $C$. auris infections, for which there is a dire need to develop effective therapies.

Supplementary Materials: The following are available online at http://www.mdpi.com/2309-608X/5/4/92/s1, Figure S1: Chemical structures of miltefosine and iodoquinol.

Author Contributions: Conceptualization, J.L.L.-R. and G.W.; Methodology, J.L.L.-R. and G.W.; Experimentation, G.W. with assistance of N.H.; Data Analysis. G.W. and J.L.L.-R., Original Draft Preparation, G.W., Writing-Review and Editing, G.W. and J.L.L.-R.; Funding Acquisition, J.L.L.-R.

Funding: This work was supported by NIH grant R21AI140823 from the National Institute of Allergy and Infectious Diseases to JLLR. Additional support was provided by the Margaret Batts Tobin Foundation, San Antonio, TX. GW was the recipient of a Science, Mathematics, and Research for Transformation (SMART) fellowship provided by the Department of Defense.

Acknowledgments: The authors are indebted to Medicines for Malaria Venture (MMV, Switzerland) for providing the Pathogen Box ${ }^{\circledR}$ Library.

Conflicts of Interest: The authors declare no conflict of interest. The funders had no role in study design, data collection and analysis, decision to publish, or preparation of the manuscript, and the content is solely the responsibility of the authors.

\section{References}

1. Banerjee, S.N.; Emori, T.G.; Culver, D.H.; Gaynes, R.P.; Jarvis, W.R.; Horan, T.; Edwards, J.R.; Tolson, J.; Henderson, T.; Martone, W.J.; et al. Secular trends in nosocomial primary bloodstream infections in the United States, 1980-1989. Am. J. Med. 1991, 91, S86-S89. [CrossRef]

2. Beck-Sague, C.; Jarvis, W.R.; National Nosocomial Infections Surveillance System. Secular trends in the epidemiology of nosocomial fungal infections in the United States, 1980-1990. J. Infect. Dis. 1993, 167, 1247-1251. [CrossRef] [PubMed]

3. Pfaller, M.A.; Diekema, D.J. Epidemiology of invasive candidiasis: A persistent public health problem. Clin. Microbiol. Rev. 2007, 20, 133-163. [CrossRef] [PubMed]

4. Fagan, R.P.; Edwards, J.R.; Park, B.J.; Fridkin, S.K.; Magill, S.S. Incidence trends in pathogen-specific central line-associated bloodstream infections in US intensive care units, 1990-2010. Infect. Control Hosp. Epidemiol. 2013, 34, 893-899. [CrossRef] [PubMed]

5. Gudlaugsson, O.; Gillespie, S.; Lee, K.; Vande Berg, J.; Hu, J.; Messer, S.; Herwaldt, L.; Pfaller, M.; Diekema, D. Attributable mortality of nosocomial candidemia, revisited. Clin. Infect. Dis. 2003, 37, 1172-1177. [CrossRef] 
6. Friedman, D.Z.P.; Schwartz, I.S. Emerging Fungal Infections: New Patients, New Patterns, and New Pathogens. J. Fungi 2019, 5, 67. [CrossRef]

7. Satoh, K.; Makimura, K.; Hasumi, Y.; Nishiyama, Y.; Uchida, K.; Yamaguchi, H. Candida auris sp. nov., a novel ascomycetous yeast isolated from the external ear canal of an inpatient in a Japanese hospital. Microbiol. Immunol. 2009, 53, 41-44. [CrossRef]

8. Lee, W.G.; Shin, J.H.; Uh, Y.; Kang, M.G.; Kim, S.H.; Park, K.H.; Jang, H.C. First three reported cases of nosocomial fungemia caused by Candida auris. J. Clin. Microbiol. 2011, 49, 3139-3142. [CrossRef]

9. Chowdhary, A.; Voss, A.; Meis, J.F. Multidrug-resistant Candida auris: 'New kid on the block' in hospital-associated infections? J. Hosp. Infect. 2016, 94, 209-212. [CrossRef]

10. Chowdhary, A.; Sharma, C.; Meis, J.F. Candida auris: A rapidly emerging cause of hospital-acquired multidrug-resistant fungal infections globally. PLoS Pathog. 2017, 13, e1006290. [CrossRef]

11. Al-Siyabi, T.; Al Busaidi, I.; Balkhair, A.; Al-Muharrmi, Z.; Al-Salti, M.; Al'Adawi, B. First report of Candida auris in Oman: Clinical and microbiological description of five candidemia cases. J. Infect. 2017, 75, 373-376. [CrossRef] [PubMed]

12. Arauz, A.B.; Caceres, D.H.; Santiago, E.; Armstrong, P.; Arosemena, S.; Ramos, C.; Espinosa-Bode, A.; Borace, J.; Hayer, L.; Cedeno, I.; et al. Isolation of Candida auris from 9 patients in Central America: Importance of accurate diagnosis and susceptibility testing. Mycoses 2017. [CrossRef] [PubMed]

13. Lockhart, S.R.; Etienne, K.A.; Vallabhaneni, S.; Farooqi, J.; Chowdhary, A.; Govender, N.P.; Colombo, A.L.; Calvo, B.; Cuomo, C.A.; Desjardins, C.A.; et al. Simultaneous Emergence of Multidrug-Resistant Candida auris on 3 Continents Confirmed by Whole-Genome Sequencing and Epidemiological Analyses. Clin. Infect. Dis. 2017, 64, 134-140. [CrossRef]

14. Vallabhaneni, S.; Kallen, A.; Tsay, S.; Chow, N.; Welsh, R.; Kerins, J.; Kemble, S.K.; Pacilli, M.; Black, S.R.; Landon, E.; et al. Investigation of the First Seven Reported Cases of Candida auris, a Globally Emerging Invasive, Multidrug-Resistant Fungus-United States, May 2013-August 2016. MMWR Morb. Mortal. Wkly. Rep. 2016, 65, 1234-1237. [CrossRef] [PubMed]

15. Oh, B.J.; Shin, J.H.; Kim, M.N.; Sung, H.; Lee, K.; Joo, M.Y.; Shin, M.G.; Suh, S.P.; Ryang, D.W. Biofilm formation and genotyping of Candida haemulonii, Candida pseudohaemulonii, and a proposed new species (Candida auris) isolates from Korea. Med. Mycol. 2011, 49, 98-102. [CrossRef]

16. De Jong, A.W.; Hagen, F. Attack, Defend and Persist: How the Fungal Pathogen Candida auris was Able to Emerge Globally in Healthcare Environments. Mycopathologia 2019, 184, 353-365. [CrossRef]

17. Schelenz, S.; Hagen, F.; Rhodes, J.L.; Abdolrasouli, A.; Chowdhary, A.; Hall, A.; Ryan, L.; Shackleton, J.; Trimlett, R.; Meis, J.F.; et al. First hospital outbreak of the globally emerging Candida auris in a European hospital. Antimicrob. Resist. Infect. Control 2016, 5, 35. [CrossRef]

18. Piedrahita, C.T.; Cadnum, J.L.; Jencson, A.L.; Shaikh, A.A.; Ghannoum, M.A.; Donskey, C.J. Environmental Surfaces in Healthcare Facilities are a Potential Source for Transmission of Candida auris and Other Candida Species. Infect. Control Hosp. Epidemiol. 2017, 38, 1107-1109. [CrossRef]

19. Abdolrasouli, A.; Armstrong-James, D.; Ryan, L.; Schelenz, S. In vitro efficacy of disinfectants utilised for skin decolonisation and environmental decontamination during a hospital outbreak with Candida auris. Mycoses 2017, 60, 758-763. [CrossRef]

20. Kean, R.; Sherry, L.; Townsend, E.; McKloud, E.; Short, B.; Akinbobola, A.; Mackay, W.G.; Williams, C.; Jones, B.L.; Ramage, G. Surface disinfection challenges for Candida auris: An in-vitro study. J. Hosp. Infect. 2018, 98, 433-436. [CrossRef]

21. Short, B.; Brown, J.; Delaney, C.; Sherry, L.; Williams, C.; Ramage, G.; Kean, R. Candida auris exhibits resilient biofilm characteristics in vitro: Implications for environmental persistence. J. Hosp. Infect. 2019. [CrossRef] [PubMed]

22. Ledwoch, K.; Maillard, J.Y. Candida auris Dry Surface Biofilm (DSB) for Disinfectant Efficacy Testing. Materials 2018, 12, 18. [CrossRef] [PubMed]

23. Rutala, W.A.; Kanamori, H.; Gergen, M.F.; Sickbert-Bennett, E.E.; Weber, D.J. Susceptibility of Candida auris and Candida albicans to 21 germicides used in healthcare facilities. Infect. Control Hosp. Epidemiol. 2019, 40, 380-382. [CrossRef] [PubMed]

24. Adams, E.; Quinn, M.; Tsay, S.; Poirot, E.; Chaturvedi, S.; Southwick, K.; Greenko, J.; Fernandez, R.; Kallen, A.; Vallabhaneni, S.; et al. Candida auris in Healthcare Facilities, New York, USA, 2013-2017. Emerg. Infect. Dis. 2018, 24, 1816-1824. [CrossRef] [PubMed] 
25. Chatterjee, S.; Alampalli, S.V.; Nageshan, R.K.; Chettiar, S.T.; Joshi, S.; Tatu, U.S. Draft genome of a commonly misdiagnosed multidrug resistant pathogen Candida auris. BMC Genom. 2015, 16, 686. [CrossRef] [PubMed]

26. Sarma, S.; Upadhyay, S. Current perspective on emergence, diagnosis and drug resistance in Candida auris. Infect. Drug Resist. 2017, 10, 155-165. [CrossRef] [PubMed]

27. Walia, K.; Chowdhary, A.; Ohri, V.C.; Chakrabarti, A. Multidrug-resistant Candida auris: Need for alert among microbiologists. Indian J. Med. Microbiol. 2017, 35, 436. [CrossRef]

28. Centers for Disease Control and Prevention. Antifungal Susceptibility Testing and Interpretation. Available online: https://www.cdc.gov/fungal/Candida-auris/c-auris-antifungal.html (accessed on 24 July 2019).

29. Lockhart, S.R. Candida auris and multidrug resistance: Defining the new normal. Fungal Genet Biol 2019, 131, 103243. [CrossRef]

30. Clancy, C.J.; Nguyen, M.H. Emergence of Candida auris: An International Call to Arms. Clin. Infect. Dis. 2017, 64, 141-143. [CrossRef]

31. Sherry, L.; Ramage, G.; Kean, R.; Borman, A.; Johnson, E.M.; Richardson, M.D.; Rautemaa-Richardson, R. Biofilm-Forming Capability of Highly Virulent, Multidrug-Resistant Candida auris. Emerg. Infect. Dis. 2017, 23, 328-331. [CrossRef]

32. Kean, R.; Delaney, C.; Rajendran, R.; Sherry, L.; Metcalfe, R.; Thomas, R.; McLean, W.; Williams, C.; Ramage, G. Gaining insights from candida biofilm heterogeneity: One size does not fit all. J. Fungi 2018, 4, 12. [CrossRef] [PubMed]

33. Kean, R.; Ramage, G. Combined Antifungal Resistance and Biofilm Tolerance: The Global Threat of Candida auris. mSphere 2019, 4, e00458-19. [CrossRef] [PubMed]

34. Butts, A.; Krysan, D.J. Antifungal drug discovery: Something old and something new. PLoS Pathog. 2012, 8, e1002870. [CrossRef]

35. Nosengo, N. New tricks for old drugs. Nature 2016, 534, 314-316. [CrossRef] [PubMed]

36. Ashburn, T.T.; Thor, K.B. Drug repositioning: Identifying and developing new uses for existing drugs. Nat. Rev. Drug Discov. 2004, 3, 673-683. [CrossRef] [PubMed]

37. Kaul, G.; Shukla, M.; Dasgupta, A.; Chopra, S. Update on drug-repurposing: Is it useful for tackling antimicrobial resistance? Future Microbiol. 2019, 14, 829-831. [CrossRef]

38. Veale, C.G.L. Unpacking the Pathogen Box-An Open Source Tool for Fighting Neglected Tropical Disease. ChemMedChem 2019, 14, 386-453. [CrossRef]

39. Centers For Disease Control and Prevention. Antibiotic Resistance (AR) Isolate Bank. Available online: https://www.cdc.gov/drugresistance/resistance-bank/ (accessed on 20 August 2019).

40. Clinical and Laboratory Standards Institute. Reference Method for Broth Dilution Antifungal Susceptibility Testing of Yeasts; Approved Standard, 2nd ed.; CLSI document M27-A3; Clinical and Laboratory Standards Institute: Wayne, PA, USA, 2008.

41. Pierce, C.G.; Uppuluri, P.; Tristan, A.R.; Wormley, F.L., Jr.; Mowat, E.; Ramage, G.; Lopez-Ribot, J.L. A simple and reproducible 96-well plate-based method for the formation of fungal biofilms and its application to antifungal susceptibility testing. Nat. Protoc. 2008, 3, 1494-1500. [CrossRef]

42. Pierce, C.G.; Uppuluri, P.; Tummala, S.; Lopez-Ribot, J.L. A 96 Well Microtiter Plate-based Method for Monitoring Formation and Antifungal Susceptibility Testing of Candida albicans Biofilms. JoVE J. Vis. Exp. 2010, 44, e2287. [CrossRef]

43. Ramage, G.; Vandewalle, K.; Wickes, B.L.; Lopez-Ribot, J.L. Characteristics of biofilm formation by Candida albicans. Rev. Iberoam. Micol. 2001, 18, 163-170.

44. Wiederhold, N.P. Antifungal resistance: Current trends and future strategies to combat. Infect. Drug Resist. 2017, 10, 249-259. [CrossRef] [PubMed]

45. Sears, D.; Schwartz, B.S. Candida auris: An emerging multidrug-resistant pathogen. Int. J. Infect. Dis. 2017, 63, 95-98. [CrossRef] [PubMed]

46. Vila, T.; Lopez-Ribot, J.L. Screening the Pathogen Box for Identification of Candida albicans Biofilm Inhibitors. Antimicrob. Agents Chemother. 2017, 61. [CrossRef] [PubMed]

47. Mayer, F.L.; Kronstad, J.W. Discovery of a Novel Antifungal Agent in the Pathogen Box. mSphere 2017, 2. [CrossRef] [PubMed]

48. Verweij, J.; Planting, A.; van der Burg, M.; Stoter, G. A dose-finding study of miltefosine (hexadecylphosphocholine) in patients with metastatic solid tumours. J. Cancer Res. Clin. Oncol. 1992, 118, 606-608. [CrossRef] [PubMed] 
49. Verweij, J.; Gandia, D.; Planting, A.S.; Stoter, G.; Armand, J.P. Phase II study of oral miltefosine in patients with squamous cell head and neck cancer. Eur. J. Cancer 1993, 29, 778-779. [CrossRef]

50. Planting, A.S.; Stoter, G.; Verweij, J. Phase II study of daily oral miltefosine (hexadecylphosphocholine) in advanced colorectal cancer. Eur. J. Cancer 1993, 29, 518-519. [CrossRef]

51. Smorenburg, C.H.; Seynaeve, C.; Bontenbal, M.; Planting, A.S.; Sindermann, H.; Verweij, J. Phase II study of miltefosine $6 \%$ solution as topical treatment of skin metastases in breast cancer patients. Anti-Cancer Drugs 2000, 11, 825-828. [CrossRef]

52. Sundar, S.; Rosenkaimer, F.; Makharia, M.K.; Goyal, A.K.; Mandal, A.K.; Voss, A.; Hilgard, P.; Murray, H.W. Trial of oral miltefosine for visceral leishmaniasis. Lancet 1998, 352, 1821-1823. [CrossRef]

53. Jha, T.K.; Sundar, S.; Thakur, C.P.; Bachmann, P.; Karbwang, J.; Fischer, C.; Berman, J.; Voss, A. Miltefosine, an Oral Agent, for the Treatment of Indian Visceral Leishmaniasis. N. Engl. J. Med. 1999, 341, 1795-1800. [CrossRef]

54. Soto, J.; Toledo, J.; Gutierrez, P.; Nicholls, R.S.; Padilla, J.; Engel, J.; Berman, J.; Fischer, C.; Voss, A. Treatment of American Cutaneous Leishmaniasis with Miltefosine, an Oral Agent. Clin. Infect. Dis. 2001, 33, 57-61. [CrossRef] [PubMed]

55. Sundar, S.; Jha, T.K.; Thakur, C.P.; Engel, J.; Sindermann, H.; Fischer, C.; Berman, J.; Junge, K.; Bryceson, A. Oral Miltefosine for Indian Visceral Leishmaniasis. N. Engl. J. Med. 2002, 347, 1739-1746. [CrossRef] [PubMed]

56. Bhattacharya, S.K.; Jha, T.K.; Sundar, S.; Thakur, C.P.; Engel, J.; Sindermann, H.; Berman, J.D.; Junge, K.; Karbwang, J.; Bryceson, A.D.M. Efficacy and Tolerability of Miltefosine for Childhood Visceral Leishmaniasis in India. Clin. Infect. Dis. 2004, 38, 217-221. [CrossRef] [PubMed]

57. Soto, J.; Arana, B.A.; Toledo, J.; Rizzo, N.; Vega, J.C.; Diaz, A.; Junge, K.; Luz, P.; Gutierrez, M.; Junge, J.E.; et al. Miltefosine for New World Cutaneous Leishmaniasis. Clin. Infect. Dis. 2004, 38, 1266-1272. [CrossRef]

58. Soto, J.; Toledo, J.; Valda, L.; Balderrama, M.; Rea, I.; Parra, R.; Fuentelsaz, C.; Ardiles, J.; Soto, P.; Molleda, F.; et al. Treatment of Bolivian Mucosal Leishmaniasis with Miltefosine. Clin. Infect. Dis. 2007, 44, 350-356. [CrossRef]

59. Bhattacharya, S.K.; Sinha, P.K.; Sundar, S.; Thakur, C.P.; Jha, T.K.; Pandey, K.; Das, V.R.; Kumar, N.; Lal, C.; Verma, N.; et al. Phase 4 trial of miltefosine for the treatment of Indian visceral leishmaniasis. J. Infect. Dis. 2007, 196, 591-598. [CrossRef]

60. Dorlo, T.P.; Balasegaram, M.; Beijnen, J.H.; de Vries, P.J. Miltefosine: A review of its pharmacology and therapeutic efficacy in the treatment of leishmaniasis. J. Antimicrob. Chemother. 2012, 67, 2576-2597. [CrossRef]

61. Food and Drug Administration. Full Prescribing Information: Impavido; Food and Drug Administration: Hampton, VA, USA, 2014.

62. Linam, W.M.; Ahmed, M.; Cope, J.R.; Chu, C.; Visvesvara, G.S.; da Silva, A.J.; Qvarnstrom, Y.; Green, J. Successful treatment of an adolescent with Naegleria fowleri primary amebic meningoencephalitis. Pediatrics 2015, 135, e744-e748. [CrossRef]

63. Vila, T.V.; Chaturvedi, A.K.; Rozental, S.; Lopez-Ribot, J.L. In Vitro Activity of Miltefosine against Candida albicans under Planktonic and Biofilm Growth Conditions and In Vivo Efficacy in a Murine Model of Oral Candidiasis. Antimicrob. Agents Chemother. 2015, 59, 7611-7620. [CrossRef]

64. Compain, F.; Botterel, F.; Sitterle, E.; Paugam, A.; Bougnoux, M.E.; Dannaoui, E. In vitro activity of miltefosine in combination with voriconazole or amphotericin B against clinical isolates of Scedosporium spp. J. Med. Microbiol. 2015, 64, 309-311. [CrossRef]

65. Rossi, D.C.P.; Spadari, C.C.; Nosanchuk, J.D.; Taborda, C.P.; Ishida, K. Miltefosine is fungicidal to Paracoccidioides spp. yeast cells but subinhibitory concentrations induce melanisation. Int. J. Antimicrob. Agents 2017, 49, 465-471. [CrossRef] [PubMed]

66. Quaesaet, L.; Stindel, E.; Lanternier, F.; Williams, T.; Jaffuel, S.; Moalic, E.; Garcia Hermoso, D.; Lortholary, O.; Ansart, S. Miltefosine-based regimen as salvage therapy in Lomentospora prolificans bone and joint infection. Med. Mal. Infect. 2018, 48, 63-65. [CrossRef] [PubMed]

67. Spadari, C.C.; Vila, T.; Rozental, S.; Ishida, K. Miltefosine Has a Postantifungal Effect and Induces Apoptosis in Cryptococcus Yeasts. Antimicrob. Agents Chemother. 2018, 62. [CrossRef] 
68. Spadari, C.C.; de Bastiani, F.; Lopes, L.B.; Ishida, K. Alginate nanoparticles as non-toxic delivery system for miltefosine in the treatment of candidiasis and cryptococcosis. Int. J. Nanomed. 2019, 14, 5187-5199. [CrossRef] [PubMed]

69. Kuhlmann, F.M.; Fleckenstein, J.M. Antiparasitic Agents. In Infectious Diseases; Elsevier: Amsterdam, The Netherlands, 2017; pp. 1345-1372. [CrossRef]

70. American Association of Pediatrics Committee on Drugs. Clioquinol (Iodochlorhydroxyquin, Vioform) and Iodoquinol (Diiodohydroxyquin): Blindness and Neuropathy. Peadiatrics 1990, 86, 797-798.

71. Burnett, B.P.; Mitchell, C.M. Antimicrobial activity of iodoquinol 1\%-hydrocortisone acetate $2 \%$ gel against ciclopirox and clotrimazole. Cutis 2008, 82, 273-280.

72. Lawung, R.; Cherdtrakulkiat, R.; Nabu, S.; Prachayasittikul, S.; Isarankura-Na-Ayudhya, C.; Prachayasittikul, V. Repositioning of 8-hydroxyquinoline derivatives as a new promising candidate for combating multidrug resistant Neisseria gonorrhoeae. EXCLI J. 2018, 17, 840-846. [CrossRef]

73. Wall, G.; Chaturvedi, A.K.; Wormley, F.L.; Wiederhold, N.P.; Patterson, H.P.; Patterson, T.F.; Lopez-Ribot, J.L. Screening a Repurposing Library for Inhibitors of Multidrug-Resistant Candida auris Identifies Ebselen as a Repositionable Candidate for Antifungal Drug Development. Antimicrob. Agents Chemother. 2018, 62. [CrossRef]

74. De Oliveira, H.C.; Monteiro, M.C.; Rossi, S.A.; Peman, J.; Ruiz-Gaitan, A.; Mendes-Giannini, M.J.S.; Mellado, E.; Zaragoza, O. Identification of Off-Patent Compounds That Present Antifungal Activity Against the Emerging Fungal Pathogen Candida auris. Front. Cell. Infect. Microbiol. 2019, 9, 83. [CrossRef]

75. Dorlo, T.P.; van Thiel, P.P.; Huitema, A.D.; Keizer, R.J.; de Vries, H.J.; Beijnen, J.H.; de Vries, P.J. Pharmacokinetics of miltefosine in Old World cutaneous leishmaniasis patients. Antimicrob. Agents Chemother. 2008, 52, 2855-2860. [CrossRef]

(C) 2019 by the authors. Licensee MDPI, Basel, Switzerland. This article is an open access article distributed under the terms and conditions of the Creative Commons Attribution (CC BY) license (http://creativecommons.org/licenses/by/4.0/). 